\title{
Identificación de nuevos péptidos de una biblioteca de despliegue en fagos con un anticuerpo monoclonal específico a la proteína $\mathbf{N}$ del virus PRRS
}

\author{
Identification of novel peptides of a phage display library with specific monoclonal antibody \\ to the $\mathrm{N}$ protein of PRRS virus
}

\author{
A Villa-Mancera ${ }^{a^{*}}$, A Reynoso-Palomara ${ }^{\mathrm{a}}$ F Utrera-Quintana ${ }^{\mathrm{a}}$, A Córdova-Izquierdo ${ }^{\mathrm{b}}$, \\ J Olivares-Pérez ${ }^{\mathrm{c}}$, M Zambrano-González ${ }^{\mathrm{a}}$, A Trejo-Córdova ${ }^{\mathrm{d}}$, L Carreón-Luna ${ }^{\mathrm{a}}$ \\ âFacultad de Medicina Veterinaria y Zootecnia, Benemérita Universidad Autónoma de Puebla, Tecamachalco, Puebla, México. \\ bepartamento de Producción Agrícola y Animal, Universidad Autónoma Metropolitana-Unidad Xochimilco, México, D.F. \\ 'Unidad Académica de Medicina Veterinaria y Zootecnia. Universidad Autónoma de Guerrero. Ciudad Altamirano, Guerrero, México. \\ ${ }^{\mathrm{d} U n i v e r s i d a d ~ d e l ~ P a p a l o a p a n, ~ L o m a ~ B o n i t a, ~ O a x a c a, ~ M e ́ x i c o . ~}$
}

\begin{abstract}
SUMMARY
The aim of the present study was to select phage clones from a combinatorial library of filamentous phage that mimic the $\mathrm{N}$ protein of Porcine Reproductive and Respiratory Syndrome Virus (PRRS) using a monoclonal antibody (SDOW17). An combinatorial library of random peptide 7-mer cysteine-constrained fused to a minor coat protein (pIII) of the M13 phage was used. To determine the effect of enrichment after each round of selection, the eluted phage were titrated, bacteriophages increased from $4,8 \times 10^{3}$ plaque-forming units (pfu) in the first round to $3,2 \times 10^{5} \mathrm{pfu}$ in the third round. After three rounds of panning 32 phage clones were randomly picked, each individual clone was amplified, purified and titred. The binding reactivity of phage clones with anti-PRRS antibodies was determined using a phage ELISA. Alignments of the selected clones with the published sequences of the $\mathrm{N}$ protein of PRRS virus were located at the amino terminal region and middle portion of the protein. The consensus amino acid residues of the 32 mimotopes sequenced was NYRYQ. Mimotope sequences were used to calculate the epitopes of the nucleocapsid protein by the web tool of Peptiope server with PepSurf algorithm. Two conformational epitopes against monoclonal antibody anti-protein $\mathrm{N}$ were identified, located in a different position and appeared mainly as an $\alpha$-helix. The selected mimotopes and conformational epitopes could be regarded as informative for diagnosis of disease.
\end{abstract}

Key words: N protein, PRRS, mimotopes, phage display.

\section{RESUMEN}

El objetivo del estudio fue seleccionar de una biblioteca combinatoria de fagos filamentosos clonas que mimeticen la proteína $\mathrm{N}$ del virus del Síndrome Respiratorio y Reproductivo Porcino (PRRS) utilizando un anticuerpo monoclonal (SDOW17). Se utilizó una biblioteca combinatoria de fagos filamentosos (M13) que expone aleatoriamente péptidos de 7 aminoácidos en la región N-terminal fusionado con la proteína III. Para determinar el efecto del enriquecimiento después de cada ronda de selección, los fagos eluidos fueron titulados; estos se incrementaron de $4,8 \times 10^{3}$ unidades formadoras de colonias (ufc) en la primera ronda a 3,2 × $10^{5}$ ufc en la tercera. Después de tres rondas de selección, 32 clonas fueron picadas al azar, cada clona individual fue amplificada, purificada y titulada. La reactividad de la unión de las clonas a los anticuerpos anti-PRRS fue determinado utilizando un ELISA de fagos. El alineamiento de las clonas secuenciadas con la obtenida del GenBank, ubican a estas en la región aminoterminal y porción media de la proteína $\mathrm{N}$ del vPRRS. La secuencia consenso de las 32 clonas seleccionadas fue NYRYQ. Las secuencias de los mimotopos fueron utilizadas para calcular los epitopos de la proteína N, mediante la herramienta bioinformática del servidor Peptiope con el algoritmo PepSurf. Dos epitopos conformacionales contra el anticuerpo monoclonal antiproteína $\mathrm{N}$ fueron identificados, localizados en diferentes posiciones y presentados principalmente como hélices $\alpha$. Los mimotopos seleccionados y epitopos conformacionales podrían ser considerados informativos para el diagnóstico de la enfermedad.

Palabras claves: proteína N, PRRS, mimotopos, fagos filamentosos.

\section{INTRODUCCIÓN}

El agente etiológico del Síndrome Respiratorio y Reproductivo Porcino (PRRS) es un virus envuelto, de aproximadamente 50-65 nm de diámetro, ARN de cadena sencilla y polaridad positiva; pertenece a la familia Arteriviridae,

Aceptado: 26.03.2015.

* 4 Sur 304 Col. Centro, CP 75482, Tecamachalco Puebla, México; abel.villa@gmail.com genero Arterivirus, orden Nidovirales (Cavanagh y col 1997, Veit y col 2014). El virus del PRRS es una de las enfermedades víricas más importantes de los cerdos, por ser de distribución mundial; afecta de manera importante a la industria porcina, estimándose pérdidas económicas en Estados Unidos por 560 millones de dólares por año (Neumann y col 2005). El genoma del PRRS tiene una longitud de aproximadamente $15 \mathrm{~kb}$, dos grandes marcos de lectura abierta (ORF1a, ORF1b) y un grupo de seis a diez marcos de lectura abiertos secuencia abajo del gen 1b (Allende y col 1999, Firth y col 2011, Hu y Zhang 
2014). El ORF1a y ORF1b, constituyen casi dos tercios del genoma, codificando para proteínas no estructurales (Music y Gagnon 2010). Se ha identificado una nueva proteína estructural con 51 aminoácidos codificados por un ORF5a alternativo (Johnson y col 2011). El ORF5, ORF6 y ORF7 codifican para las tres principales proteínas estructurales GP5, M y N, indispensables para la formación del virión e infectividad viral, mientras que las proteínas minoritarias (GP2a, GP3 y GP4) son escenciales para la infectividad (Wissink y col 2005).

Los ORFs 5-7 constituyen la mayor cantidad de proteínas estructurales virales que inducen importantes cantidades de anticuerpos funcionales en diversos momentos durante la infección. La proteína $\mathrm{M}$ es una proteína de membrana no glicosilada $(18 \mathrm{kDa})$ y la proteína $\mathrm{N}$ de la nucleocápside (15 kDa) es codificada por el ORF7 que elicita una elevada respuesta inmune (Dea y col 2000, Rascón-Castelo y col 2014). La región conservada de la proteína $\mathrm{N}$ del vPRRS presenta un alto grado de identidad en la secuencia de aminoácidos entre los aislados de tipo americano (96-100\%, VR2332) y europeo (94-99\%, virus Lelystad) (Meng y col 1995, Wootton y col 1998). Además, cuando se comparan las secuencias homólogas de los genotipos europeo y norteamericano exhiben una identidad a nivel de nuecleótidos y aminoácidos del $63 \%$ y $59 \%$, respectivamente (Meng y col 1995). Se ha evaluado la reactividad de 11 anticuerpos monoclonales (AcMo) contra la proteína $\mathrm{N}$, en sueros con el genotipo americano, obteniendo resultados positivos en $89 \%$ de 300 muestras (Wootton y col 1998). La proteína $\mathrm{N}$ es la más abundante (20-40\% del contenido proteínico), existiendo como un dímero (Snijder y col 2003), teniendo los cerdos una rápida respuesta de anticuerpos frente a la infección vírica. Los anticuerpos producidos contra la proteína $\mathrm{N}$ no son neutralizantes y no están correlacionados con la protección (Nelson y col 1994, Gonin y col 1999, Dea y col 2000).

Una biblioteca de despliege en fagos está basada en colecciones de partículas de bacteriófagos que expresan o despliegan aleateoriamente secuencias de péptidos en su superficie, como producto de fusión con una de las proteínas que cubren al fago (Smith y Scott 1993). Esta tecnología se ha utilizado ampliamente en el diagnóstico inmunológico para la detección, localización y cuantificación de un antígeno, así como en la identificación y caracterización de aminoácidos que intervienen en la unión de un anticuerpo a su antígeno específico (Mullen y col 2006, Gazarian y col 2012, Alban y col 2013). La identificación de epitopos o determinantes antigénicos reconocidos por anticuerpos monoclonales se ha realizado tradicionalmente probando colecciones de fragmentos peptídicos derivados del antígeno, hasta identificar el segmento mínimo de la secuencia que reacciona con el anticuerpo (Mullen y col 2006). La utilización de bibliotecas peptídicas de fagos filamentosos presenta la asociación física entre la información genética y el fenotipo, la selección y amplificación de esta información en E. coli. El objetivo del presente estudio fue seleccionar mimotopos de la proteína $\mathrm{N}$ de la nucleocápside del virus PRRS de una biblioteca combinatoria de fagos filamentosos utilizando un anticuerpo monoclonal (SDOW17).

\section{MATERIAL Y MÉTODOS}

\section{SELECCIÓN DE PÉPTIDOS DE UNA BIBLIOTECA DE FAGOS} FILAMENTOSOS

Se utilizó una biblioteca combinatoria de fagos filamentosos (M13) que expone aleatoriamente péptidos de 7 aminoácidos en la región $\mathrm{N}$-terminal fusionado con la proteína III, esta consiste en $2,7 \times 10^{9}$ secuencias electroforadas y con un título de $1,5 \times 10^{13}$ unidades formadoras de colonias por mililitro (ufc/mL) (New England Biolabs, USA).

Los péptidos fueron seleccionados con la IgG antiPRRS (SDOW17, Rural Technologies, USA). Los pozos de una placa de ELISA (Costar, Corning, NY, USA) fueron cubiertos con estreptavidina $(100 \mu \mathrm{g} / \mathrm{mL})$ por 2 horas, posteriormente se le añadió el amortiguador de bloqueo (amortiguador de fosfatos salinos [PBS] conteniendo albúmina sérica bovina [BSA] al 1\%). Después de tres lavados con PBS-Tween 20 (PBS-T) al 0,1\%, se adicionó IgG anti-PRRS acoplado a biotina $(50 \mu \mathrm{g} / \mathrm{mL})$ en $100 \mu \mathrm{l}$ de $\mathrm{PBS}, \mathrm{pH} 7,3$, cubierta en un contenedor húmedo para evitar evaporación e incubada toda la noche en agitación a $4{ }^{\circ} \mathrm{C}$. Posteriormente los pozos se bloquearon con 300 $\mu \mathrm{l}$ de amortiguador de bloqueo (PBS conteniendo BSA al $1 \%$ ) durante 1 hora a $4{ }^{\circ} \mathrm{C}$. Después de lavar los pozos en seis ocasiones con $200 \mu \mathrm{l}$ de PBS-T (PBS conteniendo Tween-20 al 0,1\%), se añadió $1,0 \times 10^{11}$ partículas de fagos en $100 \mu \mathrm{l}$ de PBS-T, incubándose por 1 hora a temperatura ambiente en agitación. Los fagos que no se unieron fueron removidos lavando con $200 \mu \mathrm{l}$ de PBS-T al 0,1\% por 10 ocasiones. Los fagos que se unieron se incubaron con $100 \mu \mathrm{l}$ de glicina- $\mathrm{HCl} 0,2 \mathrm{M}, \mathrm{pH} 2,2$ por 10 minutos a temperatura ambiente y neutralizados con Tris- $\mathrm{HCl} 1 \mathrm{M}$, pH 9,0. Una pequeña fracción se usó para titulación, el resto fue utilizado para infectar células de la cepa de $E$. coli ER2738 para la amplificación del fago. Se llevaron a cabo otras dos rondas de selección por afinidad, el primero utilizando $25 \mu \mathrm{g} / \mathrm{mL}$ de $\mathrm{IgG}$ y por último utilizando 12,5 $\mu \mathrm{g} / \mathrm{mL}$ de IgG anti-PRRS.

\section{AMPLIFICACIÓN Y TITULACIÓN DE FAGOS}

Los fagos eluidos fueron adicionados a la cepa de $E$. coli ER2738 (New England Biolabs, USA) en el medio de cultivo 2 xYT, por 4,5 horas a $37^{\circ} \mathrm{C}$ en agitación constante. El cultivo fue transferido a tubos y centrifugado a $11.000 \mathrm{rpm}$ durante 10 minutos a $4^{\circ} \mathrm{C}$. El sobrenadante fue removido a un tubo nuevo y se le adicionó una cuarta parte (v/v) de PEG 20\%-NaCl 2,5 M, precipitándose los fagos toda la noche a $4{ }^{\circ} \mathrm{C}$. El sobrenadante se centrifugó 
a $11.000 \mathrm{rpm}$ por 12 minutos y se decantó. Se resuspendió el botón con $1 \mathrm{ml}$ de PBS y se le agregó una cuarta parte (v/v) de PEG 20\%-NaCl 2,5 M. Se incubó en hielo durante 1 hora, y se centrifugó a $11.000 \mathrm{rpm}$ por 12 minutos. Posteriormente se desechó el sobrenadante y con PBS-NaN ${ }_{3}$ al $0,02 \%$ y se resuspendió el botón. Se centrifugó a $11.000 \mathrm{rpm}$ durante 2 minutos para quitar materia insoluble. Los fagos amplificados fueron titulados realizando diluciones seriadas 1:1000 en $1 \mathrm{~mL}$ de medio LB (Luria-Bertani). Un microlitro de cada dilución se adicionó a $200 \mu \mathrm{l}$ de un cultivo de E. coli ER2738 (New England Biolabs, USA) e incubó 3 minutos a $37^{\circ} \mathrm{C}$. Las células infectadas se transfirieron a un tubo que contenía $3 \mathrm{~mL}$ de top agar a $45^{\circ} \mathrm{C}$, vertiéndose posteriormente a una caja de Petri con LB agar a $37^{\circ} \mathrm{C}$ e incubadas durante 16 horas a $37^{\circ} \mathrm{C}$. Las cajas se inspeccionaron y las placas formadas fueron contadas y expresadas como ufc/mL. Posteriormente 32 clonas fueron seleccionadas al azar, cada clona seleccionada se amplificó, purificó y tituló de acuerdo con el procedimiento descrito anteriormente.

\section{ELISA DE FAGOS}

Los pozos de la placa de ELISA se cubrieron con 100 $\mu \mathrm{l}$ de IgG anti-PRRS $(10 \mu \mathrm{g} / \mathrm{mL})$ en PBS conteniendo BSA $0,2 \%$-Tween 20 al $0,2 \%$ toda la noche a $4{ }^{\circ} \mathrm{C}$ en agitación constante. Los pozos se lavaron en cinco ocasiones con PBS/Tween-20 al 0,2\% 5 minutos y posteriormente bloqueados con PBS conteniendo BSA al $1 \%$ por 1 hora a $37{ }^{\circ} \mathrm{C}$ sin agitación. $10^{10}$ partículas de fagos fueron diluidos en PBS/BSA 0,2\%-Tween $0,2 \%$ e incubados a temperatura ambiente durante 2 horas en agitación constante. Se lavaron nuevamente los pozos con PBS-T al 0,2\% por 5 ocasiones. Se adicionó el anticuerpo anti-M13-HRP (Amersham Biosciences, USA) en el amortiguador de bloqueo (PBS/BSA $1 \%$ ) en un volumen final de $200 \mu \mathrm{l}$ por pozo, incubándose durante 1 hora a temperatura ambiente sin agitación. La unión específica de los fagos se visualizó utilizando el ácido 2, 2'-azino-bis-[3-etilbenzotiazol6-sulfónico] (ABTS, Sigma, USA) en amortiguador de citratos, utilizando un volumen de $200 \mu \mathrm{l}$ por pozo. Como control negativo se utilizó el fago M13KE. La absorbancia fue determinada a $405 \mathrm{~nm}$.

\section{SECUENCIACIÓN DE DNA Y ANÁLISIS BIOINFORMÁTICO}

La secuencia de nucleótidos de los insertos del gen III fueron secuenciados con el cebador de secuenciación -96gIII 5'-HOCCC TCA TAG TTA GCG TAA CG-3' (New England Biolabs, USA) del kit de la biblioteca de exposición en fago utilizando el secuenciador automático Applied Biosystems 3730 DNA Analyzer. Las secuencias de los aminoácidos de las clonas individuales fueron alineadas con las secuencias de la proteína N del vPRRS del GenBank, utilizando el programa Clone Manager Professional Edition, versión 9.0 (Scientific and Educational Software, Cary, NC). Para el alineamiento de las secuencias de los mimotopos de la proteína $\mathrm{N}$, y obtener una secuencia consenso, se utilizó el programa MIMOX (Huang y col 2006). La estructura tridimensional de la proteína $\mathrm{N}$ fue obtenida del Banco de Datos de Proteínas (PDB: 1P65) (Doan y Dokland 2003). Para la localización de los epitopos en la proteína $\mathrm{N}$ se realizó un alineamiento conformacional en 3D entre la molécula y los mimotopos seleccionados utilizando el servidor Pepitope ${ }^{1}$ con el algoritmo para mapeo de epitopos PepSurf, el que alinea cada péptido a un gráfico que representa la superficie de la estructura tridimensional. Los epitopos fueron visualizados y editados con el programa PyMOL v.1.7.4².

\section{RESULTADOS}

\section{ENRIQUECIMIENTO DE FAGOS}

Se utilizó un anticuerpo anti-vPRRS (SDOW17) para identificar péptidos de una biblioteca combinatoria que mimeticen las características estructurales de la proteína $\mathrm{N}$. Para determinar el efecto del enriquecimiento después de cada ronda de selección, los fagos eluidos fueron titulados; estos se incrementaron de $4,8 \times 10^{3}$ ufc en la primera ronda a $3,2 \times 10^{5}$ ufc en la tercera ronda (figura 1a).

\section{UNIÓN ESPECÍFICA DE LAS CLONAS INDIVIDUALES DE FAGOS CON EL ANTICUERPO (SDOW17)}

Después de tres rondas de selección, 32 clonas fueron seleccionadas al azar, cada clona individual fue amplificada, purificada y titulada. La reactividad de la unión de las clonas a los anticuerpos anti-vPRRS fueron medidas por un ELISA por triplicado (figura 1b).

\section{ANÁLISIS DE LAS SECUENCIAS}

Treinta y dos clonas fueron secuenciadas, obteniéndose una frecuencia en el rango de 3,13 a 21,88\%. (cuadro 1). Los aminoácidos de la secuencia consenso de los mimotopos de las clonas obtenidas de la biblioteca de péptidos aleatorios expresados en fagos son presentados en el cuadro 1. Las secuencias de aminoácidos fueron alineadas con la secuencias de la proteína $\mathrm{N}$ del virus del PRRS obtenida del GenBank (ABU87632.1) (figura 2). Las secuencias QKIHLLT (clonas 1, 4 y 24), HYENSFT (clona 2), AQLSVSS (clonas 5, 12 20, 26, 27, 30 y 32) y HILRVHY (clonas 3, 10, 16, 25 y 29) se localizaron a la mitad de la proteína $\mathrm{N}$ que consta de 123 a.a., principalmente entre los 51-78 a.a. (figura 2). La secuencia NYRYQAV (clonas 9, 13, 15, 19, 21, 23, 28) fue localizada en el extremo aminoterminal y los aminoácidos en la posición

\footnotetext{
http://pepitope.tau.ac.il

2 DeLano WL. 2002. The PyMOL Molecular Graphics System. DeLano Scientific, San Carlos, California, USA; http://www.pymol.org.
} 
Cuadro 1. Secuencia de péptidos, consenso y frecuencia de clonas de fagos filamentosos seleccionados con $\operatorname{IgG}$ de ratón antiproteína N (SDOW17).

Sequence of peptides, consensus and frequency of filamentous phage clones selected with mouse anti-protein N IgG (SDOW17).

\begin{tabular}{|c|c|c|c|}
\hline Grupo & Clona & Frecuencia (\%) & Secuencia de a.a. \\
\hline 1 & $\begin{array}{c}9,13,15,19 \\
21,23,28\end{array}$ & $7(21,28)$ & - - NY R Y Q A V \\
\hline 2 & $\begin{array}{c}7,8,11,14 \\
17,18\end{array}$ & $6(18,75)$ & R R N Y R Y Q - - \\
\hline 3 & 31 & $1(3,13)$ & - - NY GY Q R G \\
\hline 4 & $\begin{array}{c}5,12,20,26 \\
27,30,32\end{array}$ & $7(21,88)$ & - A Q L S V S S - \\
\hline 5 & 6,22 & $2(6,25)$ & - - YY R R K H K \\
\hline 6 & $3,10,16,25,29$ & $5(15,63)$ & - H I L R V HY - \\
\hline 7 & 2 & $1(3,13)$ & - - HY E N S F T \\
\hline \multirow[t]{2}{*}{8} & $1,4,24$ & $3(9,38)$ & - Q K I H L L T - \\
\hline & & CONSENSO & - - NY R Y Q - - \\
\hline
\end{tabular}

101 y 102; mientras que los aminoácidos RRNYRYQ (clonas $7,8,11,14,17$ 18) y YYRRKHK (clonas 6 y 22) fueron alineados únicamente a la secuencia del extremo aminoterminal de la proteína N. La clona 31 (NYGYQRG) se ubicó en el extremo aminoterminal y los aminoácidos en la posición 37 y 38 .

Se utilizaron las secuencias de los mimotopos seleccionados de una biblioteca de fagos filamentosos y la
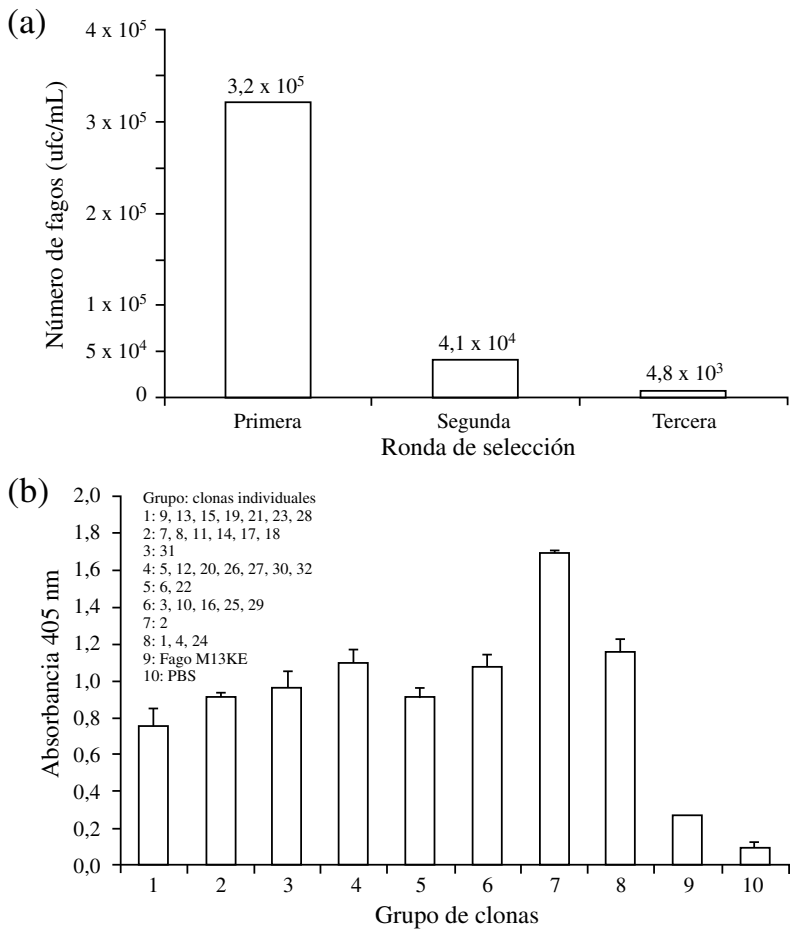

Figura 1. Enriquecimiento de fagos con un anticuerpo monoclonal (SDOW17) anti-vPRRS (a) y unión específica de bacteriófagos de clonas individuales después de tres rondas de selección (b).

Enrichment of phages with a monoclonal antibody (SDOW17) anti-PRRSV (a) and binding specificity of bacteriophage from individual clones after three rounds of selection (b).

\section{GRUPO CLONA}

$\begin{array}{cccccc}10 & 20 & 30 & 40 & 50 & 60 \\ * & * & * & * & * & *\end{array}$

ABU87632.1 MPNNNGRQQKKKKGDGQPVNQLCQMLGRIIAQQNQSRGKGPGKKSKKKSPEKPHFPLATE

$19,13,15,19,21,23,28$ MPNNNYRYQKKKKGDGQPVNQLCQMLGRIIAQQNQSRGKGPGKKSKKKSPEKPHFPLATE

$27,8,11,14,17,18$ MPRRNYRYQKKKKGDGQPVNQLCQMLGRIIAQQNQSRGKGPGKKSKKKSPEKPHFPLATE

331 MPNNYGYQRKKKGDGQPVNQLCQMLGRIIAQQNQSRGKGPGKKSKKKSPEKPHFPLATE

5 6,22 MPNNNGYYRRKKGDGQPVNQLCQMLGRIIAQQNQSRGKGPGKKSKKKSPEKPHFPLATE

$63,10,16,25,29 \quad$ MPNNNGRQKKKKGDGQPVNQLCQMLGRIIAQQNQSRGKGPGKKSKKKSPEKPHIPLATE

72 MPNNNGRQKKKKGDGQPVNQLCQMLGRIIAQQNQSRGKGPGKKSKKKSPEKPHYPLATE

$8 \quad 1,4,24$ MPNNNGRQQKKKKGDGQPVNQLCQMLGRIIAQQNQSRGKGPGKKSKKKSPQKIHFPLLTE

\section{GRUPO CLONA}

$\begin{array}{cccccc}70 & 80 & 90 & 100 & 110 & 120 \\ * & * & * & * & * & * \\ \text { TPSERQLCLSSIQTAFNGAGTCTLSDSGRISYAVEFSLPTHHTVRLIRVTASPSA } \\ \text { TPSERQLCLSSIQTAFNGAGTCTLSDSGRISYAVEFSLPTHHTVRLIRVTASPSA } \\ \text { TPSEAQLSVSSIQTAFNGAGTCTLSDSGRISYAVEFSLPTHHTVRLIRVTASPSA } \\ \text { PSSERQLCLSSIQTAFNGAGTCTLSDSGRISYAVEFSLPTHHTVRLIRVTASPSA } \\ \text { PSSERQLCLSSIQTAFNGAGTCTLSDSGRISYAVEFSLPTHHTVRLIRVTASPSA }\end{array}$

Figura 2. Alineamiento de aminoácidos con la secuencia de la proteína N del vPRRS (Número de acceso al GenBank: ABU87632.1). Alignment of amino acid with sequence of the N protein of PRRSV (GenBank Accession number: ABU87632.1). 
estructura tridimensional de la proteína N (PDB:1P65) para predecir dos epitopos conformacionales (figura 3 ). La secuencia del primer epitopo conformacional (grupo 2, 5, $6,8)$ específico para la proteína $\mathrm{N}$ del virus PRRS fueron localizados entre los aminoácidos ${ }^{12} \mathrm{VRH}^{14},{ }^{16} \mathrm{FTPS}^{19}$, ${ }^{21} \mathrm{RQ}^{22},{ }^{55} \mathrm{~L}^{55},{ }^{57} \mathrm{~T}^{57},{ }^{59} \mathrm{H}^{59},{ }^{61} \mathrm{VRL}^{63} \mathrm{y}{ }^{65} \mathrm{RVT}^{67}$; asimismo, para el epitopo 2 (grupo 1, 3, 4 y 7) ${ }^{25}$ LSSIQTAFNQGA $^{36}$, ${ }^{48} \mathrm{SY}^{49} \mathrm{y}^{51} \mathrm{~V}^{51}$. La longitud del epitopo 1 fue de 20 a.a. y para el epitopo 2, 15 a.a. En La figura 3a se muestra la representación en diagrama de cintas de los epitopos conformacionales, los a.a. del epitopo 1 (rojo) se localizaron en la hélice $\alpha$, para el epitopo 2 (verde) fueron localizados principalmente en la región de la hélice $\alpha$ y algunos en la lámina $\beta$.

\section{DISCUSIÓN}

Las bibliotecas de péptidos aleatorios, expuestos en la superficie de fagos filamentosos, se han convertido en una herramienta útil para la identificación de epitopos reconocidos por diferentes moléculas de selección como anticuerpos, receptores, enzimas y células (Smith 1985, Ebrahimizadeh y Rajabibazl 2014). Los fagos filamentosos exponen en su superficie secuencias peptídicas foráneas fusionadas a las proteínas de la cápside viral; siendo las más empleadas, la pVIII (proteína mayoritaria) y la pIII (proteína minoritaria, Kügler y col 2013). La secuencia de un péptido de una biblioteca seleccionado por una determinada propiedad puede ser fácilmente deducida de la secuencia de nucleótidos del fago que lo expone (Smith y Scott 1993, Ebrahimizadeh y Rajabibazl 2014). Las bibliotecas de despliege en fagos han sido usadas exitosamente para la selección de mimotopos empleando anticuerpos monoclonales o policlonales para la localización de sitios inmunológicamente activos (epitopos), los mimotopos seleccionados pueden ser utilizados en un ELISA de fagos, siendo una prueba inmunodiagnóstica simple, específica, sensible y de bajo costo (Ren y col 2010, da Silva Ribeiro y col 2010).

La proteína estructural de la nucleocápside es codificada por el ORF7, es altamente inmunogénica y ha sido utilizada principalmente para el diagnóstico, para detectar anticuerpos contra el virus del PRRS (Dea y col 2000). Varios dominios antigénicos han sido identificados en la proteína $\mathrm{N}$ de los genotipos americano y europeo. Un epitopo lineal específico común a ambos genotipos fue localizado en la región central de la proteína $\mathrm{N}$, entre los aminoácidos 50 y $66\left({ }^{50}\right.$ PEKPHFPLAAEDDIRHH ${ }^{66}$, Rodríguez y col 1997). Asimismo, el AcMo SDOW 17 reconoce un epitopo discontinuo, de la proteína de la nucleocápside del genotipo americano y europeo, que se ubica entre las regiones de aminoácidos 51-67 y 80-90 (Meulenberg y col 1998). Este epitopo incluye a tres mimotopos obtenidos en nuestro trabajo, los que pertenecen a tres grupos de secuencias distintas. El grupo 6 (clonas 3, 10, 16, 25 y 29), grupo 7 (clona 2) y grupo 8 (clonas 1,4 y 24) mostraron una frecuencia de $15,63 \%, 3,13 \%$ y $9,38 \%$, respectivamente; presentaron mimotopos discontinuos ${ }^{54} \mathrm{HI}^{55} \mathrm{y}^{63} \mathrm{LRVHY}^{67},{ }^{54} \mathrm{HY}^{55} \mathrm{y}$ ${ }^{64} \mathrm{ENSFT}^{68},{ }^{51} \mathrm{QKIH}^{54}$ y ${ }^{57} \mathrm{LLT}^{59}$. Asimismo, la secuencia del epitopo lineal identificado por Rodríguez y col (1997) incluye la secuencia del epitopo 2 conformacional obtenida en este estudio.

De 300 virus aislados del genotipo americano, el anticuerpo SDOW17 identificó a 99,4\% de los virus aislados (Nelson y col 1993). Varios experimentos han demostrado que el AcMo SDOW17 reconoce un epitopo conservado (aminoácidos 50-66 y 51-67) de la proteína $\mathrm{N}$ en los dos genotipos principales del virus de PRRS; esta secuencia coincide con los datos obtenidos en los grupos de clonas 1,2 y 3 .

a)
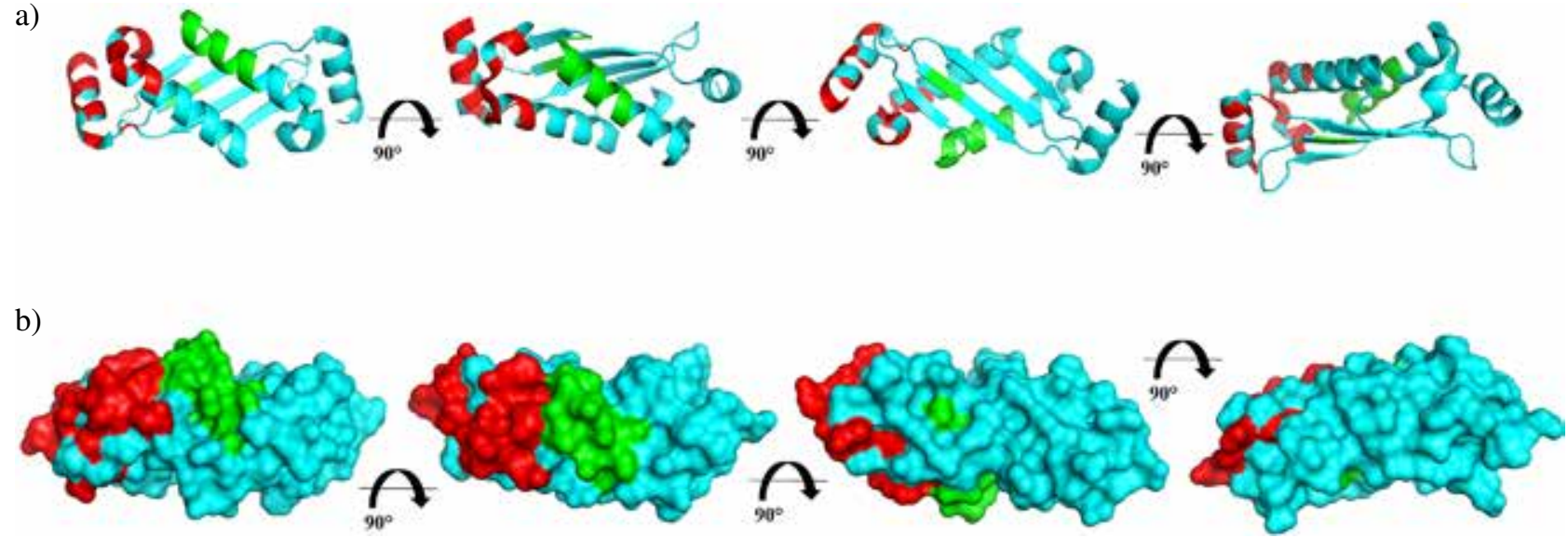

Figura 3. Localización de epitopos conformacionales específicos para IgG de ratón antiproteína N (SDOW17). Diagrama de cintas (a) y superficie (b). La predicción de epitopos (1, rojo: 2, verde) basados en mimotopos fueron obtenidos utilizando el servidor Pepitope y los epitopos conformacionales fueron modelados con PyMOL.

Location of conformational epitopes specific for mouse anti-protein $\mathrm{N}$ IgG (SDOW17). Ribbon diagrams (a) and surface (b). The predict epitopes (1, red; 2, green) based on mimotopes were obtained using the Pepitope server and conformational epitopes were modelled with PyMOL. 
El AcMo SDOW17 reconoce un epitopo discontinuo y conservado de la nucleocápside de los genotipos americano y europeo, definido por los aminoácidos 30 a 52; sin embargo, para este estudio ninguna de las clonas secuenciadas incluye a este epitopo. Asimismo, el anticuerpo SDOW17 reconoce mediante western blot proteínas de $15 \mathrm{kDa}$, que corresponde a la proteína $\mathrm{N}$ del virus del PRRS (Wootton y col 1998). La clona 31 presentó una de las menores frecuencias $(3,13 \%)$ y un epitopo discontinuo, ubicándose en el extremo aminoterminal ${ }^{4} \mathrm{NYGYQ}^{8}$ y media ${ }^{37} \mathrm{RG}^{38}$ de la proteína N. Plagemann y col 2005 demostraron que el AcMo SDOW17 se une específicamente a la proteína $\mathrm{N}$ recombinante, utilizando una placa de ELISA de un kit comercial (HerdCheck, IDEXX), el epitopo identificado corresponde a los aminoácidos del segmento 31-59, para el genotipo europeo.

En el presente trabajo la secuencia consenso de las 32 clonas seleccionadas fue NYRYQ. Además, An y col 2005 seleccionaron péptidos de una biblioteca combinatoria de fagos filamentosos de la proteína $\mathrm{N}$ utilizando el AcMo $\mathrm{N} 3 \mathrm{H} 2$, tres fagos fueron seleccionados y la secuencia consenso fue IQTAFNQGA.

El diagnóstico de la enfermedad causada por el vPRRS se basa en signos clínicos difíciles de establecer, debido a la variación en la presentación de cada granja. Existen diversas pruebas para establecer la presencia del virus, la prueba de ELISA es la más utilizada en estos procedimientos, al confiar en la naturaleza inmunogénica de la proteína $\mathrm{N}$ del virus del PRRS para la producción y detección de anticuerpos (Cai y col 2009). Un análisis comparativo de la proteína $\mathrm{N}$ indica que es altamente conservada dentro del mismo genotipo, teniendo una identidad a nivel de aminoácidos de entre $96 \%$ y $100 \%$ (Ren y col 2010). Proteínas recombinantes del vPRRS han sido utilizadas como antígenos con fines de diagnóstico para detectar anticuerpos en suero contra la proteína N. Asimismo, se han utilizado péptidos sintéticos en ELISA competitivos e indirectos para caracterizar epitopos de la proteína $\mathrm{N}$ que han sido reconocidos por varios anticuerpos monoclonales y de cerdos infectados (Plagemann y col 2006). Los mimotopos de la proteína $\mathrm{N}$ del virus PRRS obtenidos en este trabajo utilizando la técnica de despliege en fagos es un método rápido y barato para identificar péptidos que mimetizan epitopos de antígenos utilizados para diagnóstico, estos a pesar de su similitud con el antígeno natural pueden ser utilizados como antígeno en pruebas de ELISA.

En conclusión, en este estudio se identificaron ocho secuencias de péptidos de una biblioteca combinatoria que mimetizan las características estructurales de la proteína $\mathrm{N}$ del virus PRRS, uno de los mimotopos (clona 2) proporciona información acerca de una nueva secuencia que presenta alta reactividad con el anticuerpo monoclonal SDOW17. Estudios adicionales son necesarios, para probar y validar esos péptidos para la detección serológica del virus PRRS.

\section{REFERENCIAS}

Alban SM, JF de Moura, JC Minozzo, MT Mira, VT Soccol. 2013. Identification of mimotopes of Mycobacterium leprae as potential diagnostic reagents. BMC Infect Dis 13, 42.

Allende R, TL Lewis, Z Lu, DL Rock, GF Kutish, A Ali, AR Doster, FA Osorio. 1999. North American and European porcine reproductive and respiratory syndrome viruses differ in non-structural protein coding regions. J Gen Virol 80, 307-315.

An TQ, YJ Zhou, HJ Qiu, GZ Tong, YF Wang, JX Liu, JY Yang. 2005. Identification of a novel B cell epitope on the nucleocapsid protein of porcine reproductive and respiratory syndrome virus by phage display. Virus Genes 31, 81-87.

Cai JP, YD Wang, H Tse, H Xiang, KY Yuen, XY Che. 2009. Detection of asymptomatic antigenemia in pigs infected by porcine reproductive and respiratory syndrome virus (PRRSV) by a novel capture immunoassay with monoclonal antibodies against the nucleocapsid protein of PRRSV. Clin Vaccine Immunol 16, 1822-1828.

Cavanagh D. 1997. Nidovirales: a new order comprising Coronaviridae and Arteriviridae. Arch Virol 142, 629-633.

Da Silva Ribeiro V, MN Manhani, R Cardoso, CU Vieira, LR Goulart, JM Costa-Cruz. 2010. Selection of high affinity peptide ligands for detection of circulating antibodies in neurocysticercosis. Immunol Lett 129, 94-99.

Dea S, CA Ganon, H Mardassi, B Pirzadeh, D Rogan. 2000. Current knowledge on the structural proteins for porcine reproductive and respiratory syndrome (PRRS) virus: comparison of the North American and European isolates. Arch Virol 145, 659-688.

Doan DN, T Dokland. 2003. Structure of the nucleocapsid protein of porcine reproductive and respiratory syndrome virus. Structure $11,1445-1451$.

Ebrahimizadeh W, M Rajabibazl. 2014. Bacteriophage vehicles for phage display: biology, mechanism, and application. Curr Microbiol 69, 109-120.

Firth AE, JC Zevenhoven-Dobbe, NM Wills, YY Go, UB Balasuriya, JF Atkins, EJ Snijder, CC Posthuma. 2011. Discovery of a small arterivirus gene that overlaps the GP5 coding sequence and is important for virus production. J Gen Virol 92, 1097-1106.

Gazarian K, M Rowlay, T Gazarian, JE Vázquez Buchelli, M Hernández Gonzáles. 2012. Mimotope peptides selected from phage display combinatorial library by serum antibodies of pigs experimentally infected with Taenia solium as leads to developing diagnostic antigens for human neurocysticercosis. Peptides 38, 381-388.

Gonin P, B Pirzadeh, CA Gagnon, S Dea. 1999. Seroneutralization of porcine reproductive and respiratory syndrome virus correlates with antibody response to the GP5 major envelope glycoprotein. $J$ Vet Diagn Invest 11, 20-26.

Hu J, C Zhang. 2014. Porcine reproductive and respiratory syndrome virus vaccines: current status and strategies to a universal vaccine. Transbound Emerg Dis 61, 109-120.

Huang J, A Gutteridge, W Honda, M Kanehisa. 2006. MIMOX: a web tool for phage display based epitope mapping. BMC Bioinformatics 7,451 .

Johnson CR, TF Griggs, J Gnanandarajah, MP Murtaugh. 2011. Novel structural protein in porcine reproductive and respiratory syndrome virus encoded by an alternative ORF5 present in all arteriviruses. J Gen Virol 92, 1107-1116.

Kügler J, J Zantow, T Meyer, M Hust. 2013. Oligopeptide m13 phage display in pathogen research. Viruses 5, 2531-2545.

Meng XJ, PS Paul, PG Halbur, MA Lum. 1995. Phylogenetic analyses of the putative M (ORF 6) and N (ORF 7) genes of porcine reproductive and respiratory syndrome virus (PRRSV): implication for the existence of two genotypes of PRRSV in the U.S.A. and Europe. Arch Virol 140, 745-755.

Meulenberg JJ, AP van Nieuwstadt, A van Essen-Zandbergen, JN Bos-de Ruijter, JP Langeveld, RH Meloen. 1998. Localization and fine mapping of antigenic sites on the nucleocapsid protein 
$\mathrm{N}$ of porcine reproductive and respiratory syndrome virus with monoclonal antibodies. Virology 252, 106-114.

Mullen LM, SP Nair, JM Ward, AN Rycroft, B Henderson. 2006. Phage display in the study of infectious diseases. Trends Microbiol 14, 141-147.

Music N, CA Gagnon. 2010. The role of porcine reproductive and respiratory syndrome (PRRS) virus structural and non-structural proteins in virus pathogenesis. Anim Health Res Rev 11, 135-163.

Nelson EA, J Christopher-Hennings, T Drew, G Wensvoort, JE Collins, DA Benfield. 1993. Differentiation of U.S. and European isolates of porcine reproductive and respiratory syndrome virus by monoclonal antibodies. J Clin Microbiol 31, 3184-3189.

Nelson EA, J Christopher-Hennings, DA Benfield. 1994. Serum immune responses to the proteins of porcine reproductive and respiratory syndrome (PRRS) virus. $J$ Vet Diagn Invest $6,410-415$.

Neumann EJ, JB Kliebenstein, CD Johnson, JW Mabry, EJ Bush, AH Seitzinger, AL Green, JJ Zimmerman. 2005. Assessment of the economic impact of porcine reproductive and respiratory syndrome on swine production in the United States. J Am Vet Med Assoc 227, 385-392.

Plagemann PG. 2005. Epitope specificity of monoclonal antibodies to the N-protein of porcine reproductive and respiratory syndrome virus determined by ELISA with synthetic peptides. Vet Immunol Immunopathol 104, 59-68.

Plagemann PG. 2006. Peptide ELISA for measuring antibodies to $\mathrm{N}$-protein of porcine reproductive and respiratory syndrome virus. $J$ Virol Methods 134, 99-118.
Rascón-Castelo E, A Burgara-Estrella, E Mateu, J Hernández. 2015. Immunological features of the non-structural proteins of Porcine Reproductive and Respiratory Syndrome Virus. Viruses 7, 873-886.

Ren X, M Wang, J Yin, Y Ren, G Li. 2010. Heterologous expression of fused genes encoding the glycoprotein 5 from PRRSV: a way for producing functional protein in prokaryotic microorganism. J Biotechnol 147, 130-135.

Rodríguez MJ, J Sarraseca, J García, A Sánz, J Plana-Durán, J IgnacioCasal. 1997. Epitope mapping of the nucleocapsid protein of European and North American isolates of porcine reproductive and respiratory syndrome virus. J Gen Virol 78, 2269-2278.

Smith GP. 1985. Filamentous fusion phage: novel expression vectors that display cloned antigens on the virion surface. Science 228, 1315-1317.

Smith GP, JK Scott. 1993. Libraries of peptides and proteins displayed on filamentous phage. Methods Enzymol 217, 228-257.

Snijder EJ, JC Dobbe, WJ Spaan. 2003. Heterodimerization of the two major envelope proteins is essential for arterivirus infectivity. J Virol 77, 97-104.

Veit M, AK Matczuk, BC Sinhadri, E Krause, B Thaa. 2014. Membrane proteins of arterivirus particles: structure, topology, processing and function. Virus Res 194, 16-36.

Wissink EH, MV Kroese, HA van Wijk, FA Rijsewijk, JJ Meulenberg, PJ Rottier. 2005. Envelope protein requirements for the assembly of infectious virions of porcine reproductive and respiratory syndrome virus. J Virol 79, 12495-12506.

Wootton SK, EA Nelson, D Yoo. 1998. Antigenic structure of the nucleocapsid protein of porcine reproductive and respiratory syndrome virus. Clin Diagn Lab Immunol 5, 773-779. 
